\title{
CASC5 is a potential cancer-testis gene in human urinary bladder transitional cell carcinoma
}

\author{
Pankaj Kumar Singh ${ }^{1}$, Madan Lal Brahma Bhatt ${ }^{2, *}$, Prabhat Singh ${ }^{3}$, Srikanta Kumar rath ${ }^{4}$, \\ Diwakar Dalela ${ }^{5}$, Madhu Mati Goel ${ }^{6}$
}

${ }^{1}$ Department of Biochemistry, All India Institute of Medical Sciences, Vijaypur, Jammu, India;

${ }^{2}$ Department of Radiotherapy, King George's Medical University, Lucknow, Uttar Pradesh, India;

${ }^{3}$ Department of Biological Sciences, Indian Institute of Science Education and Research Berhampur, Odisha, India;

${ }^{4}$ Genotoxicity Laboratory, Division of Toxicology, CSIR-Central Drug Research Institute, Lucknow, Uttar Pradesh, India;

${ }^{5}$ Department of Urology, King George's Medical University, Lucknow, Uttar Pradesh, India;

${ }^{6}$ Department of Pathology, King George's Medical University, Lucknow, Uttar Pradesh, India.

SUMMARY Urinary Bladder cancer (UBC) is a diversified disease with an array of clinicopathological attributes. Several studies have shown that cancer susceptibility candidate 5 (CASC5) plays important roles in various types of malignancies; however its expression and clinical significance in human UBC remain largely unknown. This research study was intended to explore mRNA/protein expression pattern of CASC5 as a member of the cancer-testis (CT) gene family and assess its clinical utility in diagnostic management of patients with UBC. Quantitative real-time PCR (qRTPCR) and immunohistochemistry (IHC) was employed to appraise the detailed expression profile of CASC5 in patients with UBC. The mRNA over expression of CASC5 was detected in testis tissue and relatively high frequency 59.2\% (45 of 76) of CASC5 mRNA was detected in UBC tissues. CASC5 mRNA relative mean fold expression was also significantly $(p<0.01)$ higher in the muscleinvasive tumor tissues compared to non-muscle-invasive tumor tissues $(12.26 \pm 9.53$ vs. $4.64 \pm$ $2.50, p=0.005)$. Heterogeneous staining pattern of CASC5 protein was exclusively detected using IHC. The frequency of CASC5 protein over expression was detected in $67.7 \%$ (44 of 65) UBC patients and negative in benign prostatic hyperplasia $(\mathrm{BPH})$. Further, CASC5 protein expression was significantly $(p<0.001)$ associated with cigarette smoking habit in UBC patients. Our study findings testified that CASC5 over expression among patients with UBC as compared to controls and concludes that CASC5 is a potential CT gene in UBC.

Keywords Cancer susceptibility candidate 5, urinary bladder cancer, cancer-testis, immunotherapy, peptide vaccines

\section{Introduction}

Urinary Bladder cancer (UBC) is a diversified disease with an array of clinicopathological attributes and natural histories, which are characterized by complex networks of molecular alterations and gene expressions. With the high recurrence rate among solid tumors, UBC remains most commonly diagnosed malignancy of the urinary tract as well as second major cause of death associated with genitourinary cancer (1). Transitional cell carcinoma (TCC), which is most natural form of UBC, constitutes approximately $95 \%$ of all urothelial tumors (2). The nature of TCC is immensely diverse and characterized by two different, but associated processes: tumor recurrence and progression (3). In the developed world, the occurrence of TCC has the fourth highest incidence of all cancers and thus UBC patients is also affected from substantial morbidity and mortality (4). UBC include highly differentiated, non-invasive tumors on one side to high-grade lamina propria invasive malignant lesions on the other side. More than $60 \%$ of the early staged bladder tumors recur at least once and progress to invasive neoplasms with poor prognosis in a significant proportion of patients $(5,6)$. Although radical cystectomy (RC) has been the mainstay treatment for muscle-invasive bladder cancer (MIBC), many patients with several comorbidities are unfit for RC (7). Thus, the 5-year survival rate for MIBC patients is approximately $50 \%(8,9)$. Therefore, to upgrade the clinical management of UBC, it is crucial to identify additional potential candidates to be used in diagnostic, prognostic and therapeutic of patients. 
UBC is the only malignancy, for which immunotherapy is usually included as part of standard care (10). In non-muscle-invasive bladder cancer (NMIBC) intravesical use of the Bacillus Calmette Guerin (BCG) immunotherapy reduces the risk of local recurrence by approximately $60 \%$ by unknown mechanism, which can achieve 5-year survival rates of approximately $90 \%$ in UBC patients having unifocal disease $(11,12)$. This suggested that cancer immunotherapy targeting specific cancer testis antigens (CTAs) in UBC might be a potent and associated with less morbidity than BCG. Moreover, innovative therapy such as immunotherapy have appeared as encouraging therapeutic modality to increase overall patient survival and effective cure, which has revived enthusiasm towards characterization of tumor-specific targeted antigens (13). Thus identification of cancer-testis (CT) genes in UBC towards the development of effective and specific immunotherapy is need of the hour.

Cancer susceptibility candidate 5 (CASC5) was initially characterized as a gene involved in chromosomal translocation in leukemia and as a member of the CT gene family. It is predominantly expressed in testis, widely expressed in various human tumor cell lines, primary tumors from various tissues and organs (14-19). Till date, CASC5 expression has been documented in various diseases such as infertility, spermatogenesis and lung cancer, however its expression profiles in UBC have not been explored to date. Thus in the present study, we have evaluated quantitative mRNA expression of CASC5 in UBC. Protein expression of CASC5 was also assessed using immunohistochemistry (IHC). The expression pattern was correlated with clinical characteristics of patients to to determine clinical utility of CASC5.

\section{Materials and Methods}

\subsection{Clinical specimens}

To quantify CASC5 mRNA expression, 76 bladder tumor tissues ((male: 67; female: 9) were collected for qRT-PCR analysis. Tissue specimens were immediately immersed in RNAlater buffer (AmbionApplied Biosystems, Milan, Italy), and stored at $-80^{\circ} \mathrm{C}$ to extract RNA. Further, to characterize CASC5 immunohistochemical expression, 75 archival, formalinfixed, paraffin-embedded (FFPE) tissues (65 of bladder tumor tissues and 10 benign prostatic hyperplasia (BPH) tissues) were obtained from Pathology Department, King George's Medical University (KGMU), Lucknow, India. BPH tissues were also used as negative control in IHC analysis of CASC5. The study protocol was approved by our institutional ethics committee (Approval number: XXXIECM-II B/P13). All the bladder tumors were TCCs, which were diagnosed histologically and clinically by the two independent pathologists.

Demographic data and medical history of each patient was recorded, which is summarized in Table 1. All patients underwent cystoscopy as a reference standard for detection of UBC. All bladder tumors or suspicious lesions found were either resected or biopsied. The diagnosis of UBC was interpreted via histopathological observation. The 2004 World Health Organization (WHO) bladder tumor classification criteria were used for grading (20) and pathologic staging of bladder tumors was performed according to the 2002 tumor-lymph nodemetastasis (TNM) classification system (21).

\subsection{RNA extraction and quantitative reverse transcription-PCR}

Total RNA extraction was performed from the bladder tumor tissues using TRIzol reagent (Invitrogen, Carlsbad, CA, USA). Sixteen different normal tissues derived RNA was also purchased (Clonetech, Palo Alto, CA, USA). The RNA solution was treated with RNasefree DNase set (Qiagen, Valencia, CA, USA) as per manufacturer's instruction. RNA samples were quantified with a NanoDrop ND-1000 spectrophotometer (NanoDrop Technologies, Wilmington, DE, USA). Quality of RNA was also analyzed using the 2100 bioanalyzer (Agilent Technologies, Palo Alto, CA, USA) and stored at $-80^{\circ} \mathrm{C}$. cDNA was synthesized from $\geq 1 \mu \mathrm{g}$ RNA using Quantitect ${ }^{\circledR}$ Reverse Transcription Reagent (QIAGEN GmbH, Hilden, Germany) as per manufacturer instructions. Quantitative mRNA expression of CASC5 was analyzed using LightCycler 480 Real-Time PCR system (Roche Applied Science, Mannheim, Germany) according to the manufacturer's protocol. The PCR primer sequences were 5'-GCGCTCGTCGTCGACAA-3' and 5'-CGCCCACATAGGAATCCTTCT-3' for $\beta$-actin; and 5'-CGTGTGGACCCCAAACAAGT-3' and

Table 1. Patient clinciopathological characteristics

\begin{tabular}{|c|c|c|}
\hline $\begin{array}{l}\text { Clinicopathological } \\
\text { characteristics }\end{array}$ & $\begin{array}{c}\text { Real-time-PCR } \\
\text { Assay, } n=76,(\%)\end{array}$ & $\begin{array}{c}\text { Immunohistochemistry } \\
\text { Assay, } n=65,(\%)\end{array}$ \\
\hline \multicolumn{3}{|l|}{ Age (years, \%) } \\
\hline$\leq 45$ & $24(31.6 \%)$ & $17(26.2 \%)$ \\
\hline$>45$ & $52(68.4 \%)$ & $48(73.8 \%)$ \\
\hline \multicolumn{3}{|l|}{ Sex } \\
\hline Male & $67(88.2 \%)$ & $63(96.9 \%)$ \\
\hline Female & $9(11.8 \%)$ & $2(3.1 \%)$ \\
\hline \multicolumn{3}{|l|}{ Grade } \\
\hline Low & $33(43.4 \%)$ & $23(35.4 \%)$ \\
\hline High & $43(56.6 \%)$ & $42(64.6 \%)$ \\
\hline \multicolumn{3}{|l|}{ Stage } \\
\hline $\mathrm{Ta}$ & $3(3.9 \%)$ & $6(9.2 \%)$ \\
\hline $\mathrm{T} 1$ & $33(43.4 \%)$ & $23(35.4 \%)$ \\
\hline T2-T4 & $40(52.6 \%)$ & $36(55.4 \%)$ \\
\hline \multicolumn{3}{|l|}{ Smoking } \\
\hline No & $34(44.7 \%)$ & $29(44.6 \%)$ \\
\hline Yes & $42(55.3 \%)$ & $36(55.4 \%)$ \\
\hline \multicolumn{3}{|l|}{ Tobacco chewers } \\
\hline No & $36(47.4 \%)$ & $33(50.8 \%)$ \\
\hline Yes & $40(52.6 \%)$ & $32(49.2 \%)$ \\
\hline
\end{tabular}


5'-CACCCCATCCATTTT TGAAGA-3' for CASC5 (19). Quantitative real-time PCR thermal cycling consisted of an initial 40 cycles of denaturation at $95^{\circ} \mathrm{C}$ for $15 \mathrm{~s}$ followed by annealing at $55^{\circ} \mathrm{C}$ for $1 \mathrm{~min}$ and extension at $72^{\circ} \mathrm{C}$ for $45 \mathrm{~s}$. Each experiment was performed in triplicate, with normalization to the $\beta$-actin gene as an internal control. Human Bladder Total RNA (Clontech) was used as a reference for evaluation of CASC5 mRNA levels in bladder tumor tissues. Among normal tissues, CASC5 mRNA levels were expressed as $\mathrm{n}$-fold differences relative to $\beta$-actin (internal control) and the levels in the normal testis (calibrator).

\subsection{Immunohistochemistry}

IHC was performed on FFPE sections of bladder tumor and BPH tissues with classical protocol as described previously (22). The EnVision FLEX mini kit High pH (K802321; Dako, Glostrup, Denmark) was used to perform all steps of IHC according to manufacturer's protocol. Except primary antibody, all reagents and buffers used for IHC were from the EnVision FLEX mini kit High pH (K802321; Dako). The CASC5 protein was detected using a rabbit polyclonal antibody against CASC5 (ab95127; Abcam plc, Cambridge, UK). The tissue sections were incubated with antiCASC5 antibody (1:100) overnight at $4{ }^{\circ} \mathrm{C}$.

\subsection{Statistical analysis}

Continual data were illustrated as mean \pm SD while discrete (categorical) data were illustrated in percentages (\%). Qualitative variables were represented as numbers and percentages. Independent Student's $t$-test was performed to evaluate comparison between two independent groups. ANOVA was used to evaluate comparison between more than two groups and significance of mean difference was analyzed by Tukey's post hoc test after adjusting the multiple contrasts for significance. Associations between categorical groups (i.e., CASC5 mRNA/protein expression and clinicopathological parameters) were assessed applying the chi-square $\left(\chi^{2}\right)$ test. Two-tailed $p<0.05$ was considered to be statistically significant. Statistical analysis was performed using SPSS (Windows version 18.0) statistical software packages.

\section{Results and Discussion}

\subsection{Quantitative mRNA expression of CASC5}

The frequency of CASC 5 mRNA expression was recognized in 38.9\% (14 of 36) non-muscle-invasive and $77.5 \%$ (31 of 40 ) muscle-invasive patients. Thus, overall frequency of CASC5 mRNA expression was detected in total $59.2 \%$ (45 of 76) UBC patients. Relative mean fold expression of CASC5 was significantly $(p<0.01)$ greater in the invasive patients incomparison to non-muscle-invasive patients (12.26 \pm 9.53 vs. $4.64 \pm 2.50, p=0.005)$. Furthermore, relative mean fold expression of CASC5 was also significantly $(p<0.05)$ greater in the high grade UBC patients incomparison to low grade UBC patients $(12.56 \pm 10.64$ vs. $6.55 \pm 3.61, p=0.02$ ).

Among panel of 16 normal tissues, CASC5 mRNA expression was identified only in testis and placenta. However, over expression was noticed in testis only and relative mean fold expression level of CASC5 mRNA in placenta was 106-fold lower incomparison to testis.

The relative mean fold expression of CASC5 mRNA and its association with the UBC patient's clinicopathological characteristics are outlined in Table 2. No significant correlation was observed between CASC5 mRNA expression and clinicopathological characteristics such as patient's age, gender etc. in both the non-muscle-invasive and invasive patients. However, CASC5 mRNA relative mean fold expression was greater in older patients $v s$. younger patients, males $v s$. females, and in cigarette smokers vs. non-smokers.

Table 2. Correlation between relative mean fold CASC5 mRNA expression and clinical characteristics of UBC patients

\begin{tabular}{|c|c|c|c|c|c|c|}
\hline Characteristics & $\begin{array}{c}\text { Non-muscle-invasive } \\
\text { Mean } \pm \text { SD }\end{array}$ & $p$ value & $\begin{array}{c}\text { Muscle-invasive } \\
\text { Mean } \pm \mathrm{SD}\end{array}$ & $p$ value & $\begin{array}{c}\text { Total }(n=45) \\
\text { Mean } \pm \text { SD }\end{array}$ & $p$ value \\
\hline Age (years): & & 0.260 & & 0.205 & & 0.208 \\
\hline$\leq 45$ & $3.60 \pm 1.52(5)$ & & $9.50 \pm 2.81(12)$ & & $7.76 \pm 3.70(17)$ & \\
\hline$>45$ & $5.22 \pm 2.82(9)$ & & $14.00 \pm 11.76(19)$ & & $11.18 \pm 10.58(28)$ & \\
\hline Sex: & & 0.594 & & 0.443 & & 0.718 \\
\hline Female & $6.00 \pm 0.00$ & & $9.20 \pm 1.79(5)$ & & $8.67 \pm 2.07(6)$ & \\
\hline Male & $4.54 \pm 2.57(13)$ & & $12.85 \pm 10.31(26)$ & & $10.08 \pm 9.37(39)$ & \\
\hline Grade: & & 0.211 & & 0.194 & & 0.020 \\
\hline Low & $4.10 \pm 1.5(10)$ & & $9.00 \pm 3.43(10)$ & & $6.55 \pm 3.61(20)$ & \\
\hline High & $6.00 \pm 4.08$ & & $13.81 \pm 11.09(21)$ & & $12.56 \pm 10.64(25)$ & \\
\hline Cigarette Smoking: & & 0.127 & & 0.973 & & 0.504 \\
\hline No & $3.75 \pm 1.67(8)$ & & $12.33 \pm 7.33(12)$ & & $8.90 \pm 7.12(20)$ & \\
\hline Yes & $5.83 \pm 3.06(6)$ & & $12.21 \pm 10.89(19)$ & & $10.68 \pm 9.93(25)$ & \\
\hline
\end{tabular}

Numbers in parenthesis indicate the number of UBC patients. 


\subsection{Expression of CASC5 protein}

IHC derived heterogeneous expression of CASC5 protein was noticed in $48.3 \%$ (14 of 29) of non-muscle-invasive and $83.3 \% \%$ (30 of 36 ) muscle-invasive patients (Figure $1)$. Thus protein expression of CASC5 was recorded in $67.7 \%$ (44 of 65 ) UBC patients. Heterogenous expression of CASC5 protein was detected in $60.8 \%$ patients with low grade and $71.4 \%$ with high grade urothelial tumors respectively. There is also significant $(p<0.01)$ difference in frequency of CASC5 positive IHC expression between bladder tumor stages Ta, T1, T2-T4 (2 (4.5\%) vs. 12 (27.3\%) vs. 30 (68.2\%)).

No significant expression of CASC5 protein was detected among BPH (Figure 1D). The IHC expression of CASC5 was correlated with the clinical characteristics of the UBC patients and is outlined in Table 3. No strong association was observed between protein expression of CASC5 and patient's clinicopathological characteristics such as age, gender, grade and stage of the disease. However, CASC5 protein expression was significantly ( $p$ $<0.001$ ) associated with the cigarette smoking habit in both non-muscle-invasive and muscle-invasive patients.

$\mathrm{UBC}$ is a frequent genitourinary malignancy worldwide with approximately 160,000 deaths per year worldwide (23). It has the highest lifetime treatment costs per patient of all cancers, from diagnosis to death $(24,25)$. Although existence of improved surgical procedures and role of pelvic lymphadenectomy has well understood, invasive UBC patient's long term prognostification remains poor after treatment. Molecular mechanisms contributing UBC progression and metastasis also remain unexplained (26). Thus, UBC presents a major clinical challenge due to confined treatment choice to prevent recurrence and poor prognosis (27). Therefore, need of hour is to identify new biomarker which can be employed in early diagnosis as well as in therapeutic approach for UBC. Thus, we have evaluated mRNA and protein expression of a CT gene named CASC5 in UBC towards identification of newer diagnostic biomarker and development of active immunotherapy in carcinoma of urinary bladder (CaUB).

Recently, a number of studies showed CASC5 is abundantly expressed in testis, various human cancer
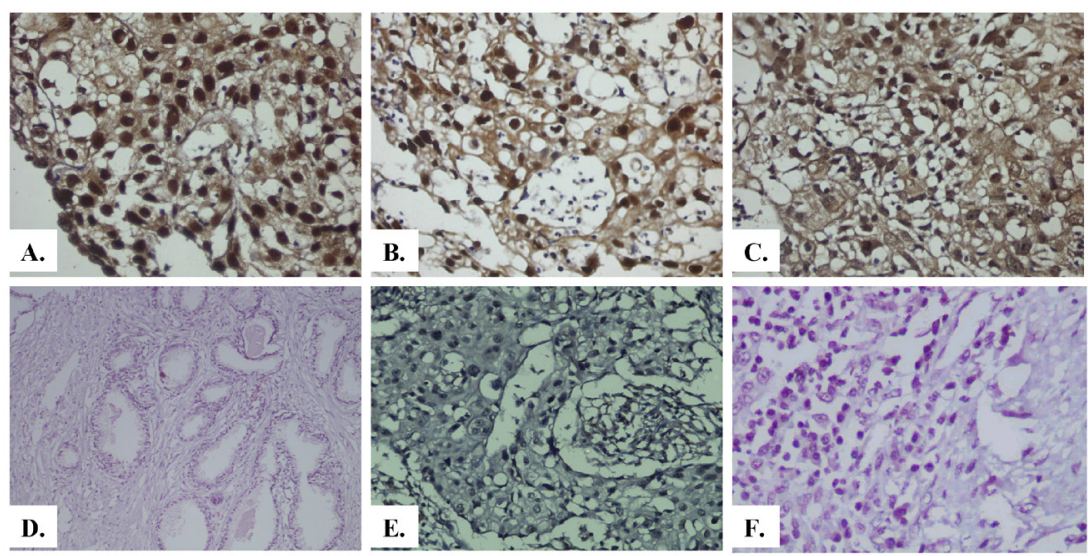

Figure 1. Heterogenous expression of CASC5 protein in surgically resected UBC (40×). UBC tissues were stained with rabbit polyclonal antibody against CASC5. (A) NMIBC showing strong positive expression. (B) MIBC showing strong positive expression. (C) MIBC showing strong positive expression. (D) $\mathrm{BPH}$ showing negative expression. (E) MIBC showing negative expression. (F) NMIBC tissue showing negative expression.

Table 3. Correlation between CASC5 protein expression and clinical characteristics of UBC patients

\begin{tabular}{|c|c|c|c|c|c|c|c|c|c|}
\hline \multirow[b]{2}{*}{ Characteristics } & \multicolumn{3}{|c|}{ Non-muscle-invasive $(n=29)$} & \multicolumn{3}{|c|}{ Muscle-invasive $(n=36)$} & \multicolumn{2}{|c|}{ Total $(n=65)$} & \multirow[b]{2}{*}{$p$ value } \\
\hline & $\begin{array}{c}\text { Negative } \\
n(\%)\end{array}$ & $\begin{array}{c}\text { Positive } \\
n(\%)\end{array}$ & $p$ value & $\begin{array}{c}\text { Negative } \\
n(\%)\end{array}$ & $\begin{array}{c}\text { Positive } \\
n(\%)\end{array}$ & $p$ value & $\begin{array}{c}\text { Negative } \\
n(\%)\end{array}$ & $\begin{array}{c}\text { Positive } \\
n(\%)\end{array}$ & \\
\hline Age (years): & & & 0.924 & & & 0.750 & & & 0.133 \\
\hline$\leq 45$ & $3(20.0 \%)$ & $3(21.4 \%)$ & & $0(0.0 \%)$ & $11(36.7 \%)$ & & $3(14.3 \%)$ & $14(31.8 \%)$ & \\
\hline$>45$ & $12(80.0 \%)$ & $11(78.6 \%)$ & & $6(100 \%)$ & $19(63.3 \%)$ & & $18(85.7 \%)$ & $30(68.2 \%)$ & \\
\hline Sex: & & & NA & & & 0.193 & & & 0.587 \\
\hline Female & $0(0.0 \%)$ & $0(0.0 \%)$ & & $1(16.7 \%)$ & $1(3.3 \%)$ & & $1(4.8 \%)$ & $1(2.3 \%)$ & \\
\hline Male & $15(100 \%)$ & $14(100 \%)$ & & $5(83.3 \%)$ & $29(96.7 \%)$ & & $20(95.2 \%)$ & $43(97.7 \%)$ & \\
\hline Grade: & & & 0.550 & & & 1.000 & & & 0.384 \\
\hline Low (G1) & $8(53.3 \%)$ & $9(64.3 \%)$ & & $1(16.7 \%)$ & $5(16.7 \%)$ & & $9(42.9 \%)$ & $14(31.8 \%)$ & \\
\hline High (G2-G3) & $7(46.7 \%)$ & $5(35.7 \%)$ & & $5(83.3 \%)$ & $25(83.3 \%)$ & & $12(57.1 \%)$ & $30(68.2 \%)$ & \\
\hline Stage: & & & 0.411 & & & NA & & & 0.007 \\
\hline $\mathrm{Ta}$ & $4(26.7 \%)$ & $2(14.3 \%)$ & & $0(0.0 \%)$ & $0(0.0 \%)$ & & $4(19.0 \%)$ & $2(4.5 \%)$ & \\
\hline $\mathrm{T} 1$ & $11(73.3 \%)$ & $12(85.7 \%)$ & & $0(0.0 \%)$ & $0(0.0 \%)$ & & $11(52.4 \%)$ & $12(27.3 \%)$ & \\
\hline $\mathrm{T} 2-\mathrm{T} 4$ & $0(0.0 \%)$ & $0(0.0 \%)$ & & $6(100 \%)$ & $30(100 \%)$ & & $6(28.6 \%)$ & $30(68.2 \%)$ & \\
\hline Cigarette Smoking: & & & 0.013 & & & $p<0.001$ & & & $p<0.001$ \\
\hline No & $13(86.7 \%)$ & $6(42.9 \%)$ & & $6(100 \%)$ & $4(13.3 \%)$ & & $19(90.5 \%)$ & $10(22.7 \%)$ & \\
\hline Yes & $2(13.3 \%)$ & $8(57.1 \%)$ & & $0(0.0 \%)$ & $26(86.7 \%)$ & & $2(9.5 \%)$ & $34(77.3 \%)$ & \\
\hline
\end{tabular}

Numbers in parenthesis indicate the number of UBC patients. 
derived cell lines, primary cancers, spermatocytes, and in spermatogenesis $(15,18,19)$. Nevertheless, the role of CASC5 in UBC remains unknown. To the best of our knowledge, our study has first time demonstrated mRNA and protein expression of CASC5 in UBC. It is notable that we detected its mRNA and protein expression in independent cohort of UBC patients. So far, only two studies have recorded CASC5 mRNA expression in primary human tumors, cancer cell lines including three UBC cell lines $(15,16)$. In contrast, our study characterized frequent expression of both CASC5 mRNA and protein expression in large number of bladder tumors irrespective of their stages and grades. This aspect of our study is a crucial step towards characterization of new CT genes as a diagnostic biomarker as well as potential target for UBC specific immunotherapy.

Under qRT-PCR, CASC5 mRNA over expression was recorded in bladder tumor tissue, testis and a very low level in placenta tissue and obtained results are in line with previous report (15). Furthermore, heterogenous expression of CASC5 protein was also seen in clinical tissue specimens of TCC patients, but, no signified expression was noted among BPH tissues. These attributes propose that CASC 5 could potentially be a transcriptional factor which may translocate between nucleus and cytoplasm. Therefore unsurprisingly, heterogenous expression pattern of CASC5 protein was observed in CaUB. These results are undeviating with past findings that observed heterogenous expression pattern of various other CT genes in breast cancer and UBC $(28,29)$. Thus in present study not only CASC5 mRNA expression is noticeable, also protein expression which is derived from IHC analysis of CASC5 in UBC of non-muscle-invasive and invasive nature. In this study, the overall frequency of CASC $5 \mathrm{mRNA} /$ protein expression was observed in 59.2\% / 67.7\% tissue specimens using qRT-PCR and IHC. Our present result originated by qRT-PCR and IHC are in agreement with the past studies that investigated CASC5 expression on smaller cohorts of tumors by RT-PCR and microarray, which reported expression of the transcript in $36-89 \%$ of tumors respectively $(15,30)$.

In our study CASC5 mRNA was not found to be significantly correlated with cigarette smoking habit of the UBC patients; however, higher relative mean fold expression was observed in tumors derived from patients with smoking habit than the ones from nonsmokers patients. Furthermore, IHC expression of CASC5 was significantly related with the smoking habit in non-muscle-invasive and muscle-invasive UBC patients. Thus our IHC findings were consistent with those of the previous study that CASC5 is the first CT gene, the expression of which is significantly related to smoking habits of the cancer patients. Thus CASC5 mRNA and protein expression pattern, which is investigated through qRT-PCR and IHC, may have an important role at the transcription level and translational events of CaUB and may have an important function in molecular initiation of UBC.

Our research study had a few limitations. First, relatively less number of bladder tumor tissue specimens was used to assess mRNA and protein expression of CASC5 in UBC. Furthermore, mRNA and IHC expression of CASC5 was analyzed on different bladder tumor tissues collected from two independent cohorts of UBC patients. Moreover, smaller number of UBC patients did not granted to perform sub analyses.

Our present study concludes upregulated mRNA and protein expression of CASC5 in CaUB, which demonstrates that CASC5 is a potential CT gene in UBC. Our study further proposes that it could be a productive target for peptide vaccines development specifically in CaUB. However, larger prospective studies are required to validate these results before these antigens can be proven for peptide vaccine mediated immunotherapy.

\section{Acknowledgements}

First author (Pankaj Kumar Singh) would like thank to Indian Council of Medial Research (ICMR), New Delhi, India for awarding Senior Research Fellowship (ICMR-SRF) (IRIS ID-2007-04520) under the guidance of corresponding author. The authors would like to thank to Naoki Itoh, Department of Urology, NTTEast Corporation Sapporo Medical Centre, Japan for providing sequence of primers specific for analyzing CASC5 mRNA expression using qRT-PCR.

\section{Funding: None.}

Conflict of Interest: The authors have no conflict of interest to disclose.

\section{References}

1. Azevedo R, Ferreira JA, Peixoto A, Neves M, Sousa N, Lima A, Santos LL. Emerging antibody-based therapeutic strategies for bladder cancer: A systematic review. J Control Release. 2015; 214:40-61.

2. Kaufman B, Trudeau M, Awada A, Blackwell K, Bachelot T, Salazar V, DeSilvio M, Westlund R, Zaks T, Spector $\mathrm{N}$, Johnston S. Lapatinib monotherapy in patients with HER2-overexpressing relapsed or refractory inflammatory breast cancer: final results and survival of the expanded HER2+ cohort in EGF103009, a phase II study. The Lancet Oncol. 2009; 10:581-588.

3. Volanis D, Kadiyska T, Galanis A, Delakas D, Logotheti S, Zoumpourlis V. Environmental factors and genetic susceptibility promote urinary bladder cancer. Toxicol Lett. 2010; 193:131-137.

4. Jemal A, Siegel R, Xu J, Ward E. Cancer statistics, 2010. CA Cancer J Clin. 2010; 60:277-300.

5. Zaravinos A, Lambrou GI, Volanis D, Delakas D, Spandidos DA. Spotlight on differentially expressed genes in urinary bladder cancer. PloS one. 2011; 
6:e18255.

6. van Rhijn BW, Burger M, Lotan Y, Solsona E, Stief CG, Sylvester RJ, Witjes JA, Zlotta AR. Recurrence and progression of disease in non-muscle-invasive bladder cancer: from epidemiology to treatment strategy. European Urol. 2009; 56:430-442.

7. Kim YJ, Byun SJ, Ahn H, Kim CS, Hong BS, Yoo S, Lee JL, Kim YS. Comparison of outcomes between trimodal therapy and radical cystectomy in muscle-invasive bladder cancer: a propensity score matching analysis. Oncotarget. 2017; 25:68996-69004.

8. Stenzl A, Cowan NC, De Santis M, Kuczyk MA, Merseburger AS, Ribal MJ, Sherif A, Witjes JA. Treatment of muscle-invasive and metastatic bladder cancer: update of the EAU guidelines. Eur Urol. 2011; 59:1009-1018.

9. Sternberg CN, Donat SM, Bellmunt J, Millikan RE, Stadler W, De Mulder P, Sherif A, von der Maase H, Tsukamoto T, Soloway MS. Chemotherapy for bladder cancer: treatment guidelines for neoadjuvant chemotherapy, bladder preservation, adjuvant chemotherapy, and metastatic cancer. Urology. 2007; 69:62-79.

10. Tadin T, Krpina K, Stifter S, Babarovic E, Fuckar Z, Jonjic N. Lower cyclooxygenase-2 expression is associated with recurrence of solitary non-muscle invasive bladder carcinoma. Diagn Pathol. 2012; 7:152.

11. Dyrskjot L, Zieger K, Kissow Lildal T, Reinert T, Gruselle O, Coche T, Borre M, Orntoft TF. Expression of MAGE-A3, NY-ESO-1, LAGE-1 and PRAME in urothelial carcinoma. Br J Cancer. 2012; 107:116-122.

12. Sharma P, Shen Y, Wen S, Yamada S, Jungbluth AA, Gnjatic S, Bajorin DF, Reuter VE, Herr H, Old LJ, Sato E. CD8 tumor-infiltrating lymphocytes are predictive of survival in muscle-invasive urothelial carcinoma. Proc Natl Acad Sci U S A. 2007; 104:3967-3972.

13. Zhong J, Chen Y, Liao X, Li J, Wang H, Wu C, Zou X, Yang G, Shi J, Luo L, Liu L, Deng J, Tang A. Testis expressed 19 is a novel cancer-testis antigen expressed in bladder cancer. Tumour Biol. 2016; 37:7757-7765.

14. Urata YN, Takeshita F, Tanaka H, Ochiya T, Takimoto M. Targeted knockdown of the kinetochore protein D40/ Knl-1 inhibits human cancer in a p53 status-independent manner. Sci Rep. 2015; 5:13676.

15. Takimoto M, Wei G, Dosaka-Akita H, Mao P, Kondo S, Sakuragi N, Chiba I, Miura T, Itoh N, Sasao T, Koya RC, Tsukamoto T, Fujimoto S, Katoh H, Kuzumaki N. Frequent expression of new cancer/testis gene D40/ AF15q14 in lung cancers of smokers. Br J Cancer. 2002; $86: 1757-1762$.

16. Cui Y, Zhang C, Ma S, Guo W, Cao W, Guan F. CASC5 is a potential tumour driving gene in lung adenocarcinoma. Cell Biochem Funct. 2020; 38:733-742.

17. Hayette S, Tigaud I, Vanier A, Martel S, Corbo L, Charrin C, Beillard E, Deleage G, Magaud JP, Rimokh R. $A F 15 q 14$, a novel partner gene fused to the $M L L$ gene in an acute myeloid leukaemia with a $\mathrm{t}(11 ; 15)(\mathrm{q} 23 ; \mathrm{q} 14)$. Oncogene. 2000; 19:4446-4450.

18. Sasao $\mathrm{T}$, Itoh $\mathrm{N}$, Takano $\mathrm{H}$, Watanabe $\mathrm{S}$, Wei G, Tsukamoto T, Kuzumaki N, Takimoto M. The protein encoded by cancer/testis gene D40/AF15q14 is localized in spermatocytes, acrosomes of spermatids and ejaculated spermatozoa. Reproduction. 2004; 128:709-716.

19. Sasao T, Takimoto M, Itoh N, Maeda T, Tanaka T, Masumori N, Tsukamoto T. Testis cancer gene D40 expression and its relationship with clinicopathological features in infertile men. Int J Urol. 2011; 18:175-179.

20. Eble JN, Sauter G, Epstein JI, Sesterhenn IA (eds.). Pathology and Genetics of Tumours of the Urinary System and Male Genital Organs. IARC Press, Lyon, France, 2004.

21. Greene FL, Page DL, FIeming ID, Fritz A, Balch CM, Haller DG, Morrow M. AJCC Cancer Staging Manual. Springer-Verlag, New York, 2002.

22. Qin ZK, Yang JA, Ye YL, Zhang X, Xu LH, Zhou FJ, Han H, Liu ZW, Song LB, Zeng MS Expression of Bmi1 is a prognostic marker in bladder cancer. BMC cancer. 2009; 9:61.

23. Stojnev S, Ristic-Petrovic A, Velickovic LJ, Krstic M, Bogdanovic D, Khanh do T, Ristic A, Conic I, Stefanovic V. Prognostic significance of mucin expression in urothelial bladder cancer. Int J Clin Exp Pathol. 2014; 7:4945-4958.

24. Santos F, Dragomir A, Zakaria AS, Kassouf W, Aprikian A. Health-care services utilization and costs associated with radical cystectomy for bladder cancer: a descriptive population-based study in the province of Quebec, Canada. BMC Health Serv Res. 2015; 15:308.

25. Yeung C, Dinh T, Lee J. The health economics of bladder cancer: an updated review of the published literature. Pharmacoeconomics. 2014; 32:1093-1104.

26. Cookson MS. The surgical management of muscle invasive bladder cancer: a contemporary review. Semin Radiat Oncol. 2005; 15:10-18.

27. Zhang Z, Zhang G, Kong C, Zhan B, Dong X, Man X. METTL13 is downregulated in bladder carcinoma and suppresses cell proliferation, migration and invasion. Sci Rep. 2016; 6:19261.

28. Zhou X, Yang F, Zhang T, Zhuang R, Sun Y, Fang L, Zhang C, Ma Y, Huang G, Ma F, Song C, Jin B. Heterogeneous expression of CT10, CT45 and GAGE7 antigens and their prognostic significance in human breast carcinoma. Jpn J Clin Oncol. 2013; 43:243-250.

29. Sharma P, Shen Y, Wen S, Bajorin DF, Reuter VE, Old LJ, Jungbluth AA. Cancer-testis antigens: expression and correlation with survival in human urothelial carcinoma. Clin Cancer Res. 2006; 12:5442-5447.

30. Curioni-Fontecedro A, Nuber N, Mihic-Probst D, Seifert B, Soldini D, Dummer R, Knuth A, van den Broek M, Moch H. Expression of MAGE-C1/CT7 and MAGE-C2/ CT10 predicts lymph node metastasis in melanoma patients. PloS one. 2011; 6:e21418.

Received August 28, 2021; Revised December 24, 2021; Accepted December 28, 2021

*Address correspondence to:

M.L.B. Bhatt, Department of Radiotherapy, King George's Medical University, Lucknow, Uttar Pradesh, India 226003.

Email: mlbbhatt@yahoo.in 